\title{
Healthcare Integrity and Protection Data Bank
}

\section{Jo An Leonce, JD}

In an effort to battle health care fraud and abuse, the Department of Health and Human Services ("HHS") has launched the Healthcare Integrity and Protection Data Bank ("HIPDB"). Health plans using the data bank will be capable of more thorough checks on the qualifications of those with whom they seek to contract, employ, or credential. The purpose of the data bank is to effectuate the wide dissemination of information concerning providers' offenses to government agencies and health plans in order to prevent providers from evading the consequences of their offenses by relocating to other states. The final rule implementing the data bank was published on October 26, 1999 in the Federal Register. The rule took effect on the date of publication.

\section{REPORTABLE FINAL ADVERSE ACTIONS}

The following types of information will be included in the data bank:

- Actions taken by federal or state agencies concerning the licensure of any health care provider, supplier or practitioner;

- Federal or state criminal convictions against health care providers, suppliers or practitioners;

- Civil judgments, except malpractice judgments, against health care providers, suppliers or practitioners that are related to the delivery of a health care item or service;

- Exclusion of health care providers, suppliers or practitioners from participation in federal or state health care programs; and

- "Other adjudicated actions or decisions," which are defined as any final action taken by a federal or state government agency or health plan that

The above Health Law article is reprinted with permission from Health Law Trends, Spring, 2000, a publication of Washington Law Firm of Arent Fox Klintner Plotkin and Kahn, PLLC. Address correspondence: Jo An Leonce, JD, at Arent Fox, PLLC, 1050 Connecticut Avenue, Washington, DC 20036 provided some type of due process mechanism. Examples include suspension without pay, reductions in pay, termination, or other similar actions.

HIPDB complements the 10-year-old National Practitioner Data Bank ("NPDB"), which contains information such as reports of medical malpractice payments, adverse licensing actions, adverse clinical privileges actions, and adverse professional society membership actions involving physicians, dentists, and other types of health care practitioners. The Health Resources and Services Administration ("HRSA"), which currently operates the NPDB, will also manage the new data bank.

Due to the overlap in the entities required to report, those authorized to query, and the types of actions reported to the two data banks, the NPDB-HIPDB Integrated Querying and Reporting Service ("IQRS") has been created to report to and query both data banks on the Internet. Depending upon the action being reported and the applicable laws, the IQRS will automatically submit the report to the NPDB, the HIPDB, or both. Before access is authorized, those who use the data banks are required to register and certify eligibility to report or submit queries. The integrated web site can be located at www.npdb-hipdb.com. Entities required to report to the data bank must provide information on all reportable final adverse actions taken since August 21, 1996, the date of enactment of the Health Insurance Portability and Accountability Act of 1996 mandating the creation of HIPDB.

Final adverse actions are required to be reported, regardless of whether or not the action is being appealed by the subject of the report. Although settlements in which no findings or admissions of liability have been made will be excluded from reporting, any final adverse action stemming from such settlements that is otherwise reportable is to be reported to the data bank.

\section{WHO IS REQUIRED TO REPORT?}

The following entities are required to report to the data bank: 
State and federal law enforcement organizations;

- State and federal agencies that license and certify any type of health care practitioner, provider, or supplier;

- Federal agencies that administer or provide payment for health care; and

- Private health plans.

The regulation defines a health plan as any group, organization, or company providing health benefits directly or indirectly through insurance, reimbursement, or other methods. The term "health plan" is quite broad, and includes traditional health insurance plans as well as insurance agents, brokers, solicitors and consultants, insurance companies, self-insured employers, and health care purchasing groups.

Government agencies and health plans are required to report final adverse actions:

- within 30 days of the date of the action;

- within 30 days of the date that reporting entity became aware of the final adverse action; or

- by the close of the entity's next monthly reporting cycle, whichever is later.

If government agencies fail to report, the name of the agency will be published in a public report; however, health plans are subject to a civil monetary penalty of up to $\$ 25,000$ for each adverse action not reported. In order to avoid being penalized, health plans must devise systems that will flag the required information and assure that it is reported in a timely fashion.

\section{WHOSE ACTIONS MUST BE REPORTED?}

Government agencies and health plans must report adverse actions taken against health care providers, suppliers, and practitioners. "Health care providers" include HMOs, PPOs, hospitals, skilled nursing facilities, home health agencies, hospices, group medical practices, and any other health care entity that directly or indirectly contracts to provide health care services. "Health care suppliers" include but are not limited to durable medical equipment suppliers, manufacturers of health care items, pharmaceutical suppliers and manufacturers, health record services, billing and transportation services suppliers, and any individuals licensed by the state or otherwise authorized to provide health care services. "Practitioners" are individu- als licensed by the state or otherwise authorized to provide health care services.

\section{WHO MAY ACCESS THE HIPDB?}

The general public does not have access to the data bank. According to the regulation, only the government agencies and private health plans required to report to the data bank have the authority to access HIPDB's information. Subjects of reports may receive their own report. HIPDB information may be requested for the following reasons: privileging and employment, professional review, licensing, certification or registration, fraud and abuse investigation, and civil and administrative sanctions.

The operating cost of the data bank is covered by fees obtained for each query requested by a non-federal entity authorized to use HIPDB. Individual practitioners, providers and suppliers making self-queries are charged $\$ 10.00$ per query per data bank for a total of $\$ 20.00$. Fee alterations will be announced through the Federal Register. A response to a self-query takes approximately 15-20 business days. In order to self-query, a practitioner must submit a signed and notarized Practitioner Response to Information Disclosure form, which is available on the website. However, to verify the information when the report is received, HIPDB will provide a complimentary copy of the report to the health care provider, supplier, or practitioner who is the subject of the report and to the reporter of the information.

\section{Major Differences Between NPDB and} $H I P D B$

\begin{tabular}{ll}
\hline \multicolumn{1}{c}{ NPDB } & \multicolumn{1}{c}{ HIPDB } \\
\hline $\begin{array}{l}\text { Focuses on adverse } \\
\text { disciplinary actions and } \\
\text { malpractice payments }\end{array}$ & $\begin{array}{l}\text { Focuses on disciplinary and } \\
\text { licensure problems (no } \\
\text { malpractice information) }\end{array}$ \\
$\begin{array}{l}\text { Subjects are physicians and } \\
\text { dentists }\end{array}$ & $\begin{array}{l}\text { Subjects of reports are } \\
\text { health practitioners, } \\
\text { providers, and suppliers }\end{array}$ \\
$\begin{array}{l}\text { Recipients of information } \\
\text { primarily are credentialing } \\
\text { committees and } \\
\text { organziations seeking to } \\
\text { employ or contract with } \\
\text { physicians }\end{array}$ & $\begin{array}{l}\text { Recipients are credentialing } \\
\text { entities and federal and } \\
\text { state law enforcement } \\
\text { officials }\end{array}$ \\
&
\end{tabular}




\section{CORRECTING OF ERRONEOUS INFORMATION}

Agencies and health plans are required to correct erroneous information they submitted and to update changes in adverse actions. However, the final regulations do not stipulate a time period within which an error must be corrected. Agencies and health plans are penalized for failure to re- port, but there are no consequences for failure to promptly correct or update information. Moreover, individuals, entities, and their authorized agents are immune from civil liability if the report was submitted without knowledge that it was false. Therefore, entities do not have as strong a set of incentives to accurately report information as they could and as practitioners believe they should. 